Article

\title{
Design of Sustainable Senior-Friendly Community Transportation Services
}

\author{
Muxin Zhang ${ }^{1,2}$ and Younghwan Pan ${ }^{2, *}$ \\ 1 College of Media and Communication, Shandong University of Political Science and Law, \\ Jinan 250014, China; zhangmx@sdupsl.edu.cn \\ 2 Department of Smart Experience Design, Kookmin University, Seoul 02707, Korea \\ * Correspondence: peterpan@kookmin.ac.kr
}

check for updates

Citation: Zhang, M.; Pan, Y. Design of Sustainable Senior-Friendly Community Transportation Services. Sustainability 2021, 13, 13078. https:/ / doi.org/10.3390/su132313078

Academic Editors: Efthimios Bothos, Panagiotis Georgakis, Babis Magoutas and Michiel de Bok

Received: 29 September 2021 Accepted: 16 November 2021 Published: 25 November 2021

Publisher's Note: MDPI stays neutral with regard to jurisdictional claims in published maps and institutional affiliations.

Copyright: (c) 2021 by the authors. Licensee MDPI, Basel, Switzerland. This article is an open access article distributed under the terms and conditions of the Creative Commons Attribution (CC BY) license (https:// creativecommons.org/licenses/by/ $4.0 /)$.

\begin{abstract}
With the increasingly serious aging problem, getting around in communities has become an important means of socializing for older adults. This study proposes a new community agingfriendly transportation service system from the perspective of service design, so as to help realize the sustainable development of community services. To achieve this objective, the pain points and demands of older adults while traveling in communities were collected through a questionnaire survey, focus group interview, and user journey map. In addition, the grounded theory was applied to encode the qualitative data obtained in the focus group interview, so as to explore the path composition and dimension connotation of designing community transportation services. Based on the research results, we found that service strategy, service foundation, service support, and service effect are the key factors influencing customized transportation services. The established model covers the design framework of the service system, customized traffic service process, design strategy of community stakeholders, and traffic service system diagram. These research results provide references for community managers, community service providers, and designers.
\end{abstract}

Keywords: sustainability; senior-friendly community construction; transportation services; service design

\section{Introduction}

The rapid rise in population aging has become one of the most important global challenges in the 21st century. The potential impact of population aging on labor markets and economic performance and the financial pressure that many countries may face in the coming decades affect public health care systems, pensions, and social protection plans for older adults [1]. In China, those aged over 60 account for $18.7 \%$ of the population. China will continue to face the pressure of long-term unbalanced population development in the future [2]. Against the backdrop of the global aging trend, the strategic development of senior-friendly community facilities and services is necessary for communities in the future.

Community transportation is an important link between older adults and their social networks and activities. Previous studies have shown that for many older adults, community services, including family services, catering, and transportation, are an important aspect of their independence [3]. There are significant differences in community models in different countries. The United States implements the "bottom-up" community governance model, and Britain implements the highly autonomous model with less government intervention [4]. The unique community service model in China is developed with the following characteristics: (1) services are provided in a mixed vertical-horizontal structure, unlike models abroad that primarily employ social service institutions; (2) quasi-governmental elder care organizations are managed and organized by non-governmental social service organizations; and (3) services are offered by private small business service providers and volunteers, rather than professionals [5]. The main motivation of China's community services is to support family care, in contrast to that of Western countries. The role of 
the family in senior care remains the cornerstone of China's system. Therefore, families, communities, enterprises, and the government jointly share the responsibility of funding and caring for older adults. Existing community organizations have a considerable role in China's model of community service provision. China's community service is a resident welfare service established with the financial support of the government based on streets, towns, and residents' committees by mobilizing various community resources to organize and provide services. It aims to meet the various needs of community residents [6]. In recent years, as a new popular pension model, community-based older adult care has integrated the advantages of family and institutional pensions and gained the universal recognition of older adults because of its convenient and comfortable services. Seniors can live in their familiar community in addition to obtaining geriatric care and services within the local community, maintaining a certain extent of independence and dignity in life. However, there are currently few well-operated aging-friendly public transportation systems in China, and the user experience is rather poor. The travel of older adults is only subsidized by the comprehensive subsidy system, which still fails to meet the personalized travel demands of older adults. Because community transportation service providers lack professional training, and community services are carried out within a relatively small range, this paper focuses on studying the aging-friendly transportation services and effectively helps to establish new social links with them. This study is of great importance, both practically and theoretically.

In this study, the components of building an aging-friendly transportation service system were discussed from the perspective of service design. Through a questionnaire survey, focus group interview, and user journey map, the problems and needs of older adults in terms of travel were evaluated, and the grounded theory was used to encode and analyze the data gained in the focus group interview. The factors influencing customized transportation services were divided into four dimensions, namely, service strategy, service foundation, service support, and service effect. The design framework of aging-friendly transportation services proposed in this paper can comprehensively improve older people's experiences when using community aging-friendly transportation services, with the intention of providing theoretical references and practical guidance for the community service industry.

\section{Literature Review}

To explore the framework of sustainable senior-friendly community transportation services from the perspective of service design, this research mainly focused on theoretical literature regarding the development of sustainable community transportation and seniorfriendly transportation services.

\subsection{Literature Review on Sustainable Communities}

At present, community development efforts tend to realize sustainable development. Some scholars have proposed a sustainable community through a complementary combination of material and social environments [7-9]. Previous studies have examined the connotations, realization mechanisms, and the relationship between sustainable community and transportation from different research perspectives, mainly focusing on two aspects. First, regarding the construction path, many scholars have studied the framework of sustainable community development [7], spatial construction approaches [8], and multi-level models to establish the relationship between economic and cultural conditions [10]. The advocate community has led sustainable development, including strategic green ecological status [11]. Moreover, community construction should consider encouraging the participation of users [12], along with technology and enterprise participation [13]. Some scholars believe that integrating technological innovation and community action is a key component of sustainable development [14]. For example, in developing countries, the participation of the business community is a core aspect of social responsibility [15]. Second, there is an important relationship between sustainable communities and transportation [16]. The 
establishment of sustainable development indicators should include the measurement of public transport service quality [17]. Transportation should also meet the needs of different traffic participants in the community [18]. In order to improve sustainable behavior for transportation networks [19], transportation modes must be promoted to meet the needs of older adults; community design and service selection must also be strengthened [20].

Many researchers have defined sustainable communities based on the relationships among people, environment, and society. Currently available research mostly studies the theories and practices related to the way of building communities with aging-friendly transportation services from the perspectives of economics, ecology, and architecture. Although the literature supports the importance of transportation services in sustainable community construction, most studies have focused on strategies for building sustainable communities, while only mentioning contents related to transportation in its function and most noticeably failing to study sustainable community transportation services from the perspective of service design. In a word, there is not enough attention and theoretical research devoted to the complexity of community transportation and service. Thus, this lack of information challenges the establishment of effective theoretical proposals to help community service builders and designers conceive new community transportation service design ideas. Investigating current community transportation services, which are an important part of public service design, can contribute to a more complete understanding of comprehensive sustainable community design.

\subsection{Literature Review of Senior-Friendly Transportation Services}

Service design theory presents an effective perspective for analyzing senior-friendly community service challenges. First proposed in the field of management and then developed in the field of design, service design provides users with diversified experiences and eventually encompasses all the contacts in the process. Service innovation results in a systematic design framework that not only serves the aging population, but also inspires community managers [21-24]. Service design can provide services for senior-friendly groups as well as offer ideas to community managers. Previous studies have conducted research from perspectives of service design and senior-friendly products, focusing on two considerations. The first perspective regards the importance of senior-friendly transportation service construction. Some scholars discussed the impact of transportation factors on the quality of life of older people [25] who represented a diversified social composition through walking and other physical activities [26-29], and they demonstrated a positive correlation between senior citizens' perceptions of social diversity and improved means of transportation [30]. Therefore, encouraging older people to use various forms of transportation is a priority for rehabilitation. The two perspectives concern the development of senior-friendly transportation construction. Dahan et al. used supply and demand analysis to propose a conceptual model and analyzed the unbalanced relationship between American transportation supply and transportation demand [31]. Wang introduced a geographic information system as the basis for performance measurement of the system to evaluate transportation systems' sustainability and livability [32]. Some scholars have also asserted that home-based older adult care system services should include transportation and actively respond to maximize the dignity of older adults $[33,34]$. The Chinese government encourages the development of senior-friendly communities. Ling established a hierarchical framework of transportation system management from the macro level to the micro level, safeguarding spatial safety and road safety from two perspective, namely, society and architectural environment [35-38]. Yu investigated the differences between old and new communities and the needs of older adults in terms of current community services [39]. Some studies have proposed that senior-friendly overall design principles for public fitness facilities, road transportation facilities, and public cultural facilities, and system designs of barrier-free transportation and senior-friendly signage in the community should be implemented by connecting the landscape of community parks with the space $[40,41]$. 
In conclusion, scholars at home and abroad have obtained rich research results on aging in such fields as urban planning, economics, geography, and gardening, advocating for effective transportation services as a crucial aspect of senior-friendly community construction. The meaning of service design has been fully developed from the definition stage to the practical application stage. Service design can better help the community to systematically realize aging-friendly transportation services. However, there remains a lack of research on senior-friendly transportation services from the perspective of service design. In real community service scenarios, the fundamental practical problems of senior-friendly transportation in the community can be systematically addressed from the perspective of service design. Previous studies have focused on accessible design of transportation services, but they paid less attention to problems of whether these transportation services are aging-friendly. In addition to satisfying only this single aspect, they lacked empirical or systematic research and failed to propose methods and paths to effectively improve community transportation services. In addition, most of the research methods used in previous research focused on quantitative research, which has certain limitations. The combination of quantitative and qualitative research will reveal the actual travel behavior and motivation of middle-aged and older adults in the real community. This research presents an effective supplement to the preponderance of quantitative research. Secondly, based on service design theory, this paper proposes a theoretical framework for considering the interaction between transportation and senior adults to improve the implementation of service design that attends to the interests of the public to the greatest extent [25]. The ultimate goal of this research is to explore the challenges of senior-friendly transportation in sustainable communities, to design a customized service process, to enrich the existing research on transportation service in communities, and to innovate senior-friendly transportation services.

\section{Methodology}

\subsection{Participants}

The authors were clearly aware of individual differences among the respondents, which made it inappropriate to divide older adults simply by age. Therefore, based on the concept of sustainable development and only in the questionnaire survey, the investigation scope was expanded from the above 60 age group to the older population aged above 50 , to better understand the demands of the older population. First of all, respondents had characteristics typical of the samples to be examined in this study. Secondly, the data used in this study were available and complete. The authors were quite familiar with the older adults in this age group, so the acquired data for research were relatively complete.

\subsection{Research Process}

In the first stage, we conducted the questionnaire survey and focus group interview, and drew the user journey map. First, a questionnaire survey was carried out among participants aged 50-89. Secondly, from the 120 respondents, 60 participants aged 60-85 were selected for the focus group interview. Thirdly, a user journey map was drawn based on the above results to fully represent the demands and pain points of the respondents in terms of travel.

The second stage included the focus group discussion. Based on the analysis, focus group interviews were conducted, including older adults, young people, community service workers, and community service investors. The results from the focus group interviews were qualitatively analyzed. The recordings were sorted, and then encoded, grouped, and condensed to ensure the credibility of the research (See Figure 1). 


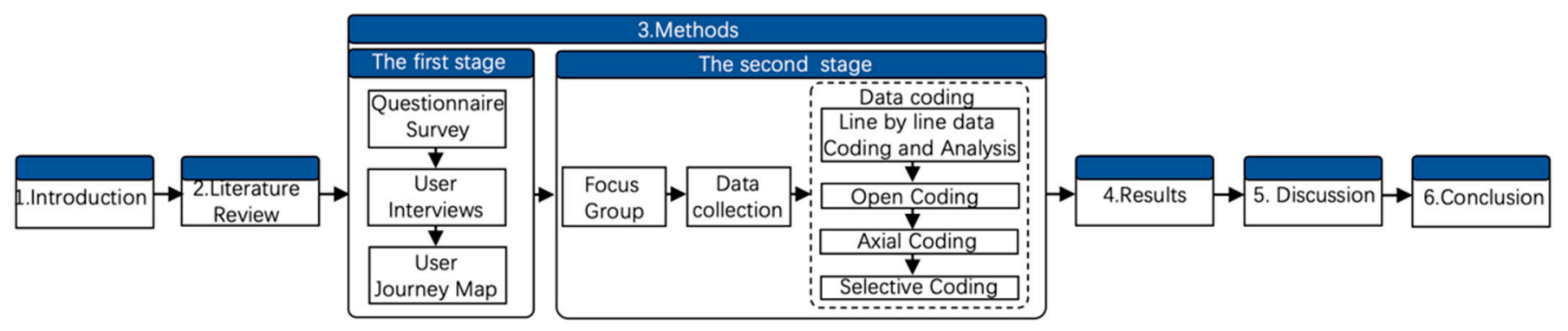

Figure 1. Research process.

\subsubsection{Phase I}

\section{A. Questionnaire Survey}

This experiment invited the participation of 120 people in the Hengxin Community, Weifang, Shandong Province, China. The participants included 30 people aged 50-59, 30 people aged $60-69,30$ people aged $70-79$, and 30 people aged $80-89$, none of whom had neurological abnormalities. Consent was obtained from each participant throughout the entire process through a signed informed consent form.

The questionnaires were designed to identify problems and needs at the initial stage of the research. The first part of the questionnaire assessed the degree of demand for community transportation services. The second part examined the degree of satisfaction with community travel facilities. The third part collected basic information from participants. In the process, researchers and community property management personnel assisted participants with completing the questionnaire, which was prepared in large-character format, also providing a pen, presbyopic glasses, and other auxiliary tools to aid participants' ease of navigation.

B. User Interviews

Table 1 presents the in-depth interview questions presented to participants.

Table 1. User interview outline.

\begin{tabular}{|c|c|}
\hline \multicolumn{2}{|r|}{ What Is the Most Important Factor of Transportation Service in the Community? } \\
\hline \multirow{4}{*}{$\begin{array}{l}\text { Before } \\
\text { travel }\end{array}$} & 1. What is your usual travel route? \\
\hline & 2. Are you satisfied with the transportation situation in your current residential area? \\
\hline & 3. Do you need customized transportation services? \\
\hline & 4. Why don't you need customized transportation services? \\
\hline \multirow{6}{*}{$\begin{array}{l}\text { During } \\
\text { travel }\end{array}$} & 5. What is your travel goal? \\
\hline & 6. What means of transportation or equipment do you usually use when? \\
\hline & 7. What obstacles or problems do you usually encounter when you travel? \\
\hline & $\begin{array}{l}\text { 8. What functions do you value more when using intelligent travel equipment? (Sharing } \\
\text { transportation information with children, detecting physical state information, real-time } \\
\text { positioning, etc.). }\end{array}$ \\
\hline & 9. What items do you think customized transportation services should have? \\
\hline & 10. What is your demand for customized transportation personalized service? \\
\hline \multirow{5}{*}{$\begin{array}{l}\text { After } \\
\text { travel }\end{array}$} & 11. What is your route to get home after your trip? \\
\hline & $\begin{array}{l}\text { 12. What do you think has changed compared with whether there is a travel service } \\
\text { or not? }\end{array}$ \\
\hline & 13. What are your suggestions for improvements in transportation services? \\
\hline & 14. What other types of transportation services do you need? \\
\hline & 15. Will you buy customized transportation services? \\
\hline
\end{tabular}


In-depth interviews were conducted to deepen the understanding of user experiences and capture insights into the respondents' use behavior and demand for transportation services in the community. The questions covered three stages, namely, before travel, during travel, and after travel. Through a telephone inquiry by customer service personnel, the invitation was screened. From the 120 participants in the questionnaire survey, 60 residents of the Community were selected for in-depth interviews. The respondents were $60-85$ years of age and included 30 men and 30 women with many years of experience living in the community. They also had considerable requirements for community transportation facilities. The entire process was agreed upon by each participant through informed consent. In-depth interviews were divided into 6 groups of 10 respondents. One researcher conducted one-on-one interviews separately, which took 30 to $45 \mathrm{~min}$ for each respondent. All respondents were given 50-yuan eggs as gifts, and each group interview took about 5 to $7 \mathrm{~h}$.

Implementation process: Prior to the interview, the research purpose was described, and the researchers recorded the entire process with the participants' consent to facilitate the recording of the results. Interviews included three parts: The first part recorded the user's feelings before traveling in detail according to their answers (10-15 $\mathrm{min})$. The second part asked about the participant's feelings during the process of travel (10-15 $\mathrm{min})$. The third part asked about the participant's feelings following travel (10-15 min). According to the respondents' answers, their experiences were captured in various stages to gain a better understanding of their travel. This in-depth interview highlighted the respondents ${ }^{\prime}$ levels of attention to travel.

\section{User Journey Map}

Organizing a visual user journey map at each stage of the journey helps researchers better understand and grasp users' emotions and feelings and better identify and understand their needs. The user journey map was divided into three stages: getting ready, being outside, and getting back. According to the visual user journey diagram in Figure 2, users had an unpleasant experience during the whole process.

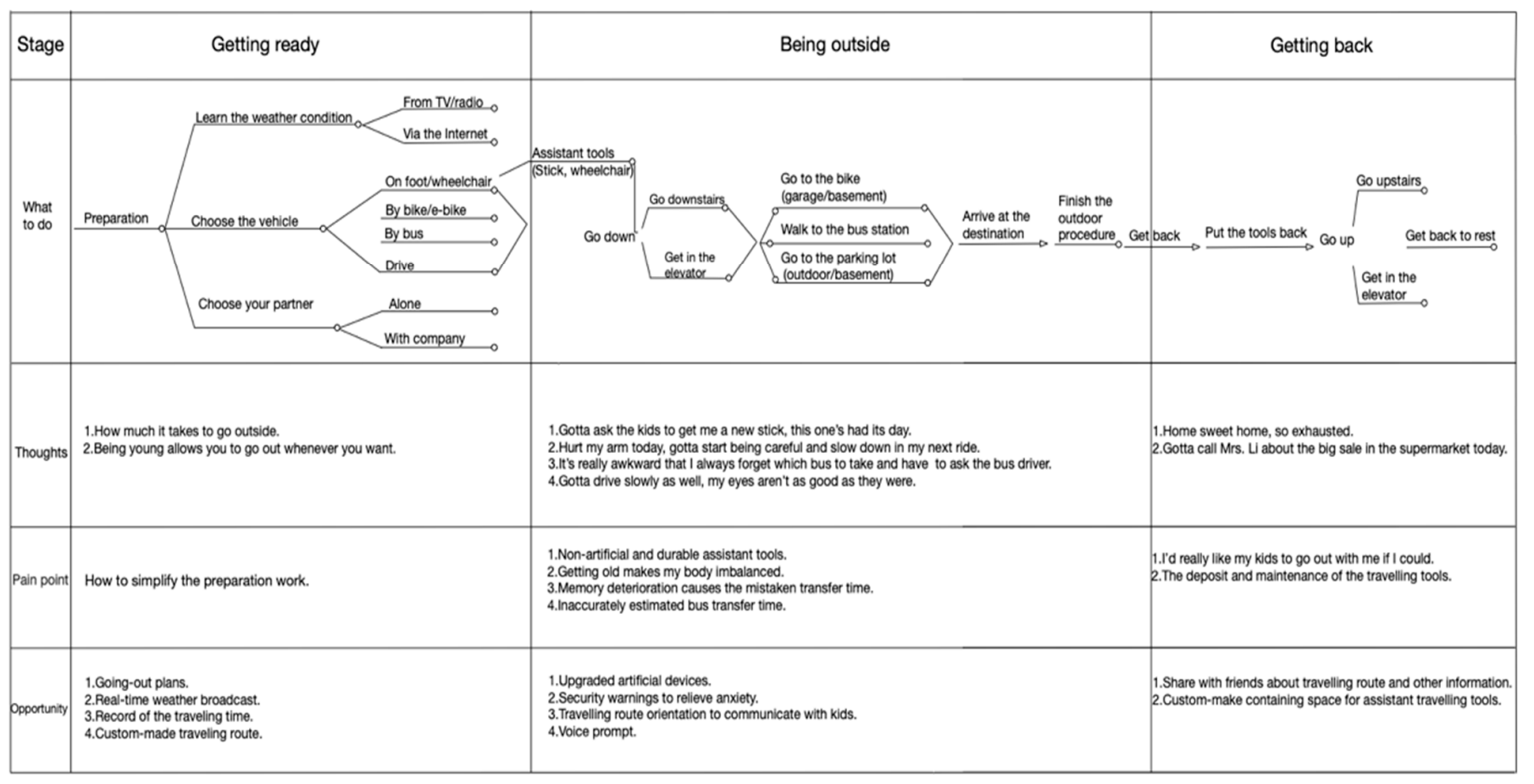

Figure 2. User journey diagram. 


\subsubsection{Phase 2}

After summarizing the user journey map, the next research stage adopted a focus group research interview method. The focus group discussion concentrated on three types of people, namely, older adults, middle-aged and young community residents, and community transportation service providers and investors. The focus group discussion was conducted in August 2021. The interviewees' ages varied from 18 to 84, with a total of 56 participants, all of whom lived in Hengxin Community, Weifang. The focus group interview sought to assess the needs and concerns of different stakeholders with regard to the community transportation services environment, transportation service facilities, and transportation services, hoping to clarify the design strategy of community transportation service through discussion. Table 2 presents information about the participants in the focus group discussion.

Table 2. Focus group participants' information.

\begin{tabular}{cccc}
\hline Stakeholders & Group & Age Range (Number) & Gender \\
\hline & 1 & $62-73(7)$ & Male (4)/Female (3) \\
Senior residents (aged 60 and above) & 2 & $60-75(7)$ & Male (3)/Female (4) \\
& 3 & $61-84(8)$ & Male (4)/Female (4) \\
\hline Young and middle-aged community & 4 & $18-48(6)$ & Male (3)/Female (3) \\
residents (18-59) & 5 & $28-57(4)$ & Male (3)/Female (2) \\
\hline Community stewards & 6 & $31-59(5)$ & Male (1)/Female (3) \\
\hline Community workers & 7 & $25-45(4)$ & Male (2)/Female (2) \\
\hline Community property management personnel & 9 & $30-50(4)$ & Male (3)/Female (3) \\
\hline Community real estate investors & 10 & $42-55(6)$ & Male (3)/Female (2) \\
\hline
\end{tabular}

\section{Results}

4.1. Data Collection and Analysis of Phase 1

4.1.1. Questionnaire Survey

A. Validity Analysis

1. Content validity: Six experts in the expert group meeting were selected to evaluate the relevance of the questionnaire content from the 120 community participants, and the cumulative frequency of items with a score of 3 or 4 were divided by the number of experts to elicit the content validity index (I-CVI) at the item level. Finally, the average value was calculated to obtain the content validity index (S-CVI) of the total items. The results showed that the I-CVI of 13 evaluation questionnaire items was 1.00, the I-CVI of each item was $0.83-1.00$, and the S-CVI of the evaluation questionnaire was 0.95 .

2. Structural validity: Exploratory factor analysis was conducted to assess the 15 items retained in the item analysis. The results demonstrated a KMO test statistic of the evaluation questionnaire of 0.936 . The factor analysis results after rotation are shown in Table 3.

Table 3. Results of factor analysis after rotation.

\begin{tabular}{lccccc}
\hline \multicolumn{1}{c}{ Item } & $\mathbf{1}$ & $\mathbf{2}$ & $\mathbf{3}$ & $\mathbf{4}$ & $\mathbf{5}$ \\
\hline Transportation safety service & 0.949 & & & & \\
Transportation and children exchange services & 0.879 & & & & \\
Transportation intelligent service program & 0.784 & & & & \\
Garage cabinet for storing travel tools & 0.669 & & & & \\
Purchase service for smart travel equipment & & 0.848 & & & \\
Transportation information service & & 0.795 & & & \\
\hline
\end{tabular}


Table 3. Cont.

\begin{tabular}{|c|c|c|c|c|c|}
\hline Item & 1 & 2 & 3 & 4 & 5 \\
\hline Continuous and complete sidewalk & & 0.679 & & & \\
\hline Community-level slow transportation system & & 0.627 & & & \\
\hline One-on-one customized transportation service & & & 0.793 & & \\
\hline Door-to-door delivery service & & & 0.773 & & \\
\hline Transportation convenience & & & & 0.857 & \\
\hline Transportation service lecture & & & & 0.806 & \\
\hline Barrier-free facilities & & & & & 0.802 \\
\hline Transportation guidance signs & & & & & 0.798 \\
\hline Illumination of road lighting at night & & & & & 0.659 \\
\hline
\end{tabular}

\section{B. Reliability Analysis}

The Cronbach's $\alpha$ coefficient of the travel information questionnaire was 0.861 , which was scored on a Likert scale from 1 to 5 in five dimensions, namely, strong agreement, agreement, indifference, acquiescence, and disagreement. The Cronbach's $\alpha$ coefficient was 0.881 , and the Cronbach's $\alpha$ coefficients of strong agreement, agreement, indifference, acquiescence, and disagreement were $0.895,0.860,0.847,0.859$, and 0.845 , respectively. Two weeks following the pre-survey, 30 participants from the pre-survey were re-investigated, eliciting a retest reliability of the questionnaire of 0.796 , and the reliability coefficients of the above dimensions were $0.815,0.831,0.845,0.839$, and 0.835 , respectively.

Conclusion: The evaluation questionnaire prepared in this research demonstrated good validity. Content and structural validity were used to evaluate the effectiveness of the questionnaire, which was confirmed to reflect the needs of the participants for transportation services and evaluate the effect of transportation services for the participants.

\subsubsection{User Interviews}

Before travel: More than $80 \%$ of the respondents indicated an intense interest in travel. As for the travel route, they usually chose a suitable means of transportation after going down a set of stairs. They had high expectations for auxiliary transportation services and aspired to enrich their retirement life through travel.

During travel: In terms of the travel goals, respondents focused on shopping and picking up their grandchildren. Regarding the benefits of travel, more than half of the respondents believed that appropriate travel was beneficial to their health, while $37 \%$ indicated that they had encountered some difficulties in the process of travel. Respondents ${ }^{\prime}$ travel needs showed the characteristics of diversity; $60 \%$ of the participants hoped to use intelligent travel devices to communicate with their children regarding travel routes and information in real time. They also confirmed that customized transportation services and transportation equipment could potentially increase their motivation for going out.

After travel: Respondents expressed different demands; $56 \%$ of the respondents indicated that they needed convenient and flexible travel services, and $32 \%$ were interested in the shuttle and special services; $12 \%$ signified that they were incapable of traveling alone without necessarily special services.

\subsubsection{User Journey Map}

It was found that the participants had unpleasant experiences in the process. Because of the complicated preparation before the travel, the participants were afraid of difficulties. The participants experienced their emotional trough during the travel. The participants had the following obvious pain points: There was no voice prompt at the bus transfer stop, so the participants often worried about missing the stop because they could not respond quickly and transfer to the bus in time; the auxiliary travel equipment was not smart enough to locate the traveling routes of older adults for their children; the participants were likely to get nervous and anxious. After traveling there was no special space for storing travel tools or corresponding maintenance services. 


\subsection{Data Collection and Analysis of Phase 2}

The result analysis of the focus group interview applied a qualitative analytical method. The researchers sorted the interview recordings by coding, grouping, and condensing them to ensure the credibility of the research.

\subsubsection{Open Coding Refines Concepts and Categories}

Open coding is the process of coding the original data word by word, labeling, logging, developing the initial concepts, and refining the categories from the original data [42,43]. The text data collected during the focus group discussion were processed using NVivo 12 software. First, the original imported sentences were sorted and classified to extract the original representative sentences related to transportation service design, and free nodes were established. A total of 432 original sentences were obtained. Second, the initial concepts were developed, continuously comparing, analyzing, and summarizing them to merge and sort the nodes formed by the initial coding. Thirty-six initial categories were identified for continuous comparison, analysis, and induction. The selected results from the process of open coding are presented in Table 4 . We listed only selected parts of the coding results because the coding process involved many original interview records in Chinese.

Table 4. Overview of grounded theory coding.

\begin{tabular}{|c|c|c|c|c|c|c|}
\hline Open Coding & $\begin{array}{l}\text { Ref } \\
\text { No. }\end{array}$ & $\begin{array}{l}\text { Files } \\
\text { (ppl) }\end{array}$ & Probability (\%) & Axial Coding & Probability (\%) & Selective Coding \\
\hline Intelligent equipment & a1 & 50 & $89 \%$ & \multirow{3}{*}{$\begin{array}{c}\text { A1 } \\
\text { Intelligent service }\end{array}$} & \multirow{3}{*}{$89 \%$} & \multirow{9}{*}{$\begin{array}{c}\text { A } \\
\text { Service } \\
\text { strategy }\end{array}$} \\
\hline Appointment service & $\mathrm{a} 2$ & 45 & $80 \%$ & & & \\
\hline Transportation service procedures & a3 & 40 & $71 \%$ & & & \\
\hline One-to-one service & $\mathrm{a} 4$ & 52 & $93 \%$ & \multirow{3}{*}{$\begin{array}{c}\mathrm{A} 2 \\
\text { Customized service }\end{array}$} & \multirow{3}{*}{$93 \%$} & \\
\hline On-demand customization & a5 & 31 & $55 \%$ & & & \\
\hline Meeting individual needs & a6 & 20 & $36 \%$ & & & \\
\hline Focus on the older adults & a7 & 36 & $64 \%$ & \multirow{3}{*}{$\begin{array}{c}\text { A3 } \\
\text { Humanized service }\end{array}$} & \multirow{3}{*}{$79 \%$} & \\
\hline Warm care & a8 & 34 & $61 \%$ & & & \\
\hline Psychological comfort & a9 & 18 & $32 \%$ & & & \\
\hline Preparation before travel & b1 & 23 & $41 \%$ & \multirow{3}{*}{$\begin{array}{c}\text { B1 } \\
\text { Travel scenario }\end{array}$} & \multirow{3}{*}{$88 \%$} & \multirow{9}{*}{$\begin{array}{c}\text { B } \\
\text { Service } \\
\text { basis }\end{array}$} \\
\hline $\begin{array}{l}\text { Travel method } \\
\text { (Together with others or alone) }\end{array}$ & b2 & 25 & $45 \%$ & & & \\
\hline Transportation scenario & b3 & 32 & $57 \%$ & & & \\
\hline Travel goal & $\mathrm{b} 4$ & 32 & $57 \%$ & \multirow{3}{*}{$\begin{array}{c}\text { B2 } \\
\text { Behavioral intention }\end{array}$} & \multirow{3}{*}{$80 \%$} & \\
\hline Intrinsic ability & b5 & 30 & $54 \%$ & & & \\
\hline External will & b6 & 23 & $41 \%$ & & & \\
\hline Cognitive law & b7 & 20 & $36 \%$ & \multirow{3}{*}{$\begin{array}{c}\text { B3 } \\
\text { Physiological } \\
\text { cognition }\end{array}$} & \multirow{3}{*}{$77 \%$} & \\
\hline Behavioral characteristics & b8 & 38 & $68 \%$ & & & \\
\hline Physiological limitation & b9 & 30 & $54 \%$ & & & \\
\hline $\begin{array}{c}\text { Community transportation } \\
\text { environment }\end{array}$ & $\mathrm{c} 1$ & 40 & $71 \%$ & \multirow{3}{*}{$\begin{array}{c}\text { C1 } \\
\text { Transportation } \\
\text { System }\end{array}$} & \multirow{3}{*}{$84 \%$} & \multirow{9}{*}{$\begin{array}{c}\text { C } \\
\text { Service } \\
\text { support }\end{array}$} \\
\hline Barrier-free design & $\mathrm{c} 2$ & 30 & $54 \%$ & & & \\
\hline Walking trail & c3 & 28 & $50 \%$ & & & \\
\hline Transportation interconnection & c4 & 48 & $86 \%$ & \multirow{3}{*}{$\begin{array}{l}\mathrm{C} 2 \\
\text { Facility improvement }\end{array}$} & \multirow{3}{*}{$86 \%$} & \\
\hline Infrastructure improvement & c5 & 45 & $80 \%$ & & & \\
\hline Lectures & c6 & 26 & $46 \%$ & & & \\
\hline Community security & c7 & 40 & $71 \%$ & \multirow{3}{*}{$\begin{array}{c}\text { C3 } \\
\text { Security }\end{array}$} & \multirow{3}{*}{$75 \%$} & \\
\hline Transportation security & c8 & 35 & $63 \%$ & & & \\
\hline Emergency and fire & c9 & 20 & $36 \%$ & & & \\
\hline
\end{tabular}


Table 4. Cont.

\begin{tabular}{|c|c|c|c|c|c|c|}
\hline Open Coding & $\begin{array}{l}\text { Ref } \\
\text { No. }\end{array}$ & $\begin{array}{l}\text { Files } \\
\text { (ppl) }\end{array}$ & Probability (\%) & Axial Coding & Probability (\%) & Selective Coding \\
\hline Direct economic benefits & $\mathrm{d} 1$ & 18 & $32 \%$ & \multirow{3}{*}{$\begin{array}{c}\mathrm{D} 1 \\
\text { Economic effect }\end{array}$} & \multirow{3}{*}{$68 \%$} & \multirow{9}{*}{$\begin{array}{c}\text { D } \\
\text { Service } \\
\text { effect }\end{array}$} \\
\hline Indirect economic benefits & $\mathrm{d} 2$ & 13 & $23 \%$ & & & \\
\hline Conversion rates & d3 & 8 & $14 \%$ & & & \\
\hline Community atmosphere & $\mathrm{d} 4$ & 34 & $60 \%$ & \multirow{3}{*}{$\begin{array}{c}\text { D2 } \\
\text { Community effect }\end{array}$} & \multirow{3}{*}{$52 \%$} & \\
\hline Customer satisfaction & $\mathrm{d} 5$ & 19 & $34 \%$ & & & \\
\hline Community resilience & d6 & 9 & $16 \%$ & & & \\
\hline Political benefit & $\mathrm{d} 7$ & 16 & $29 \%$ & \multirow{3}{*}{$\begin{array}{c}\text { D3 } \\
\text { Social effect }\end{array}$} & \multirow{3}{*}{$48 \%$} & \\
\hline Ideological and cultural benefits & $\mathrm{d} 8$ & 15 & $27 \%$ & & & \\
\hline Ecological Environment Benefit & d9 & 10 & $18 \%$ & & & \\
\hline
\end{tabular}

\subsubsection{Axial Coding Establishes the Main Category}

Axial coding aims to further refine the nature and level of categories and identify potential logical relationships between categories to develop main categories and subcategories. This research explored transportation service design, classifying it according to logical internal connections between different categories at the conceptual level and summarizing four categories (Table 5).

Table 5. Main categories formed by axial coding.

\begin{tabular}{|c|c|c|}
\hline Main Category & Corresponding Category & Category Connotation \\
\hline \multirow{3}{*}{$\begin{array}{l}\text { Service } \\
\text { strategy }\end{array}$} & Intelligent service & $\begin{array}{l}\text { Intelligent service refers to the travel call, purchase of intelligent travel tools, and } \\
\text { other intelligent transportation service procedures provided for the purpose of } \\
\text { older adults' travel. }\end{array}$ \\
\hline & Customized service & $\begin{array}{l}\text { Providing one-on-one services for older adults in the community eliminates } \\
\text { travel restrictions owing to physical limitations and helps adults exchange } \\
\text { transportation travel information with their children. }\end{array}$ \\
\hline & Humanized service & $\begin{array}{l}\text { Humanized services refer to convenient transportation services for older adults, } \\
\text { including door-to-door services such as shopping, delivery, and moving services. }\end{array}$ \\
\hline \multirow{3}{*}{$\begin{array}{l}\text { Service } \\
\text { basis }\end{array}$} & Travel scenario & $\begin{array}{c}\text { Providing one-on-one services for older adults in the community eliminates } \\
\text { travel restrictions owing } \\
\text { to physical limitations and helps adults exchange } \\
\text { transportation travel information with their children. }\end{array}$ \\
\hline & Behavioral intention & $\begin{array}{l}\text { Humanized services refer to convenient transportation services for older adults, } \\
\text { including door-to-door services, such as shopping, delivery, and } \\
\text { moving services. }\end{array}$ \\
\hline & Physiological cognition & $\begin{array}{c}\text { Physiological cognition refers to the older adult individual's level of travel } \\
\text { ability in terms of cognitive laws, behavioral characteristics, and } \\
\text { physiological constraints. }\end{array}$ \\
\hline \multirow{4}{*}{$\begin{array}{l}\text { Service } \\
\text { support }\end{array}$} & Transportation system & $\begin{array}{l}\text { The transportation system is the overall convenience of transportation in the } \\
\text { community, including the transportation environment, barrier-free facilities, and } \\
\text { walking or slow transportation. }\end{array}$ \\
\hline & Facility improvement & Facility improvement refers to the supporting facilities within the community. \\
\hline & Security & $\begin{array}{l}\begin{array}{l}\text { Security refers to the travel safety guarantee system established by } \\
\text { the community. }\end{array}\end{array}$ \\
\hline & Economic effect & $\begin{array}{l}\text { The economic effect refers to the fiscal effect of community services for older } \\
\text { adults, including increasing employment opportunities and revenue from } \\
\text { providing community services. }\end{array}$ \\
\hline \multirow[t]{2}{*}{ Service effect } & Community effect & $\begin{array}{l}\text { The community effect includes the communication and exchange between older } \\
\text { adults and the community. }\end{array}$ \\
\hline & Social effect & Social effect refers to the communication and interaction between communities. \\
\hline
\end{tabular}




\subsubsection{Selective Coding to Define Core Categories}

Selective coding identifies a core category among all the categories following systematic analysis, stringing all other genera into a coherent whole and including most of the research results in a broader theoretical scope. This research identified transportation service as the core category and focused on the core category. Its "storyline" structure was that service foundation is a realistic condition of senior-friendly transportation service in sustainable communities. Service support and service strategy are realistic paths for promoting the realization of senior-friendly community transportation service design, and service effect is both the result of transportation service and the driver for the expectation of results.

Based on the qualitative analysis, the paper concluded that in the context of seniorfriendly design, the construction of a future community transportation service should consider community transportation service system design, customized community transportation service, a community stakeholder design strategy, and a senior-friendly community service system in four dimensions, namely, service strategy, service basis, service support, and service effect. Figure 3 presents the senior-friendly transportation service model, and the four dimensions are described in detail below.

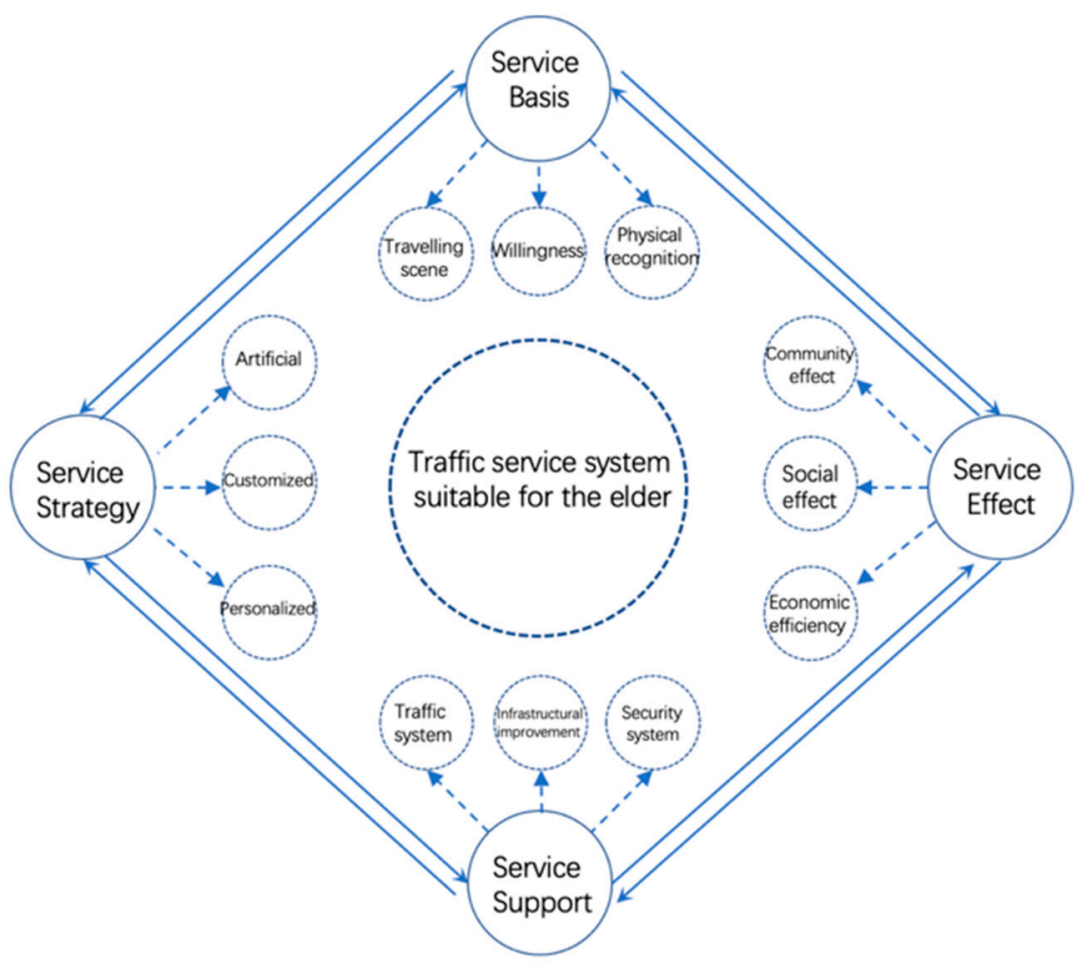

Figure 3. Senior-friendly transportation service model.

\section{Discussion}

According to the classification dimensions of the model, the discussion is carried out from four perspectives: (1) Service Strategy: Sustainable Community Customized Transportation Services; (2) Service Basis: Design Framework for Community Transportation Service System; (3) Service Support: Senior-friendly Community Service System; (4) Service Effect: Community Stakeholder Design Strategy.

\subsection{Service Strategy: Sustainable Community Customized Transportation Services}

Service process refers to the entire process of service provision and the services required in the implementation process. Process design refers to the comprehensive decision making regarding the service process for service enterprises to improve efficiency 
and benefits according to the internal and external resource structure and allocation ability of service organizations.

In the main category formed by the axial coding, this research promotes the customized services strategy to establish a customized, senior-friendly transportation service process to address the lack of senior-friendly, customized community transportation services, clarify the transportation needs of older adults as the starting point, and focus on providing customized transportation services to ensure the tracking of pre-sales, in-sales, and after-sales services of customized transportation services from the beginning. As one of the core contents of service design, the main feature of the service process is the dependence and interaction of users and focus on user interaction and service contact points, as opposed to the production process [44]. As shown in Figure 4, according to the needs of older adults, door-to-door customization should be conducted. Based on the personal physical conditions, personal preferences, and service needs of older adults, they can choose from three different service schemes: general products, partial customization, and in-depth customization. Payment would be made by the customer after reviewing the customized transportation service scheme. The contact point in the R\&D test phase is the test report. The order production, transportation logistics, and installation can be performed only after older adults have reviewed them, and a signed confirmation has been issued. The scheme, test report, confirmation, and other contact points of this process are guaranteed in different stages of customization.

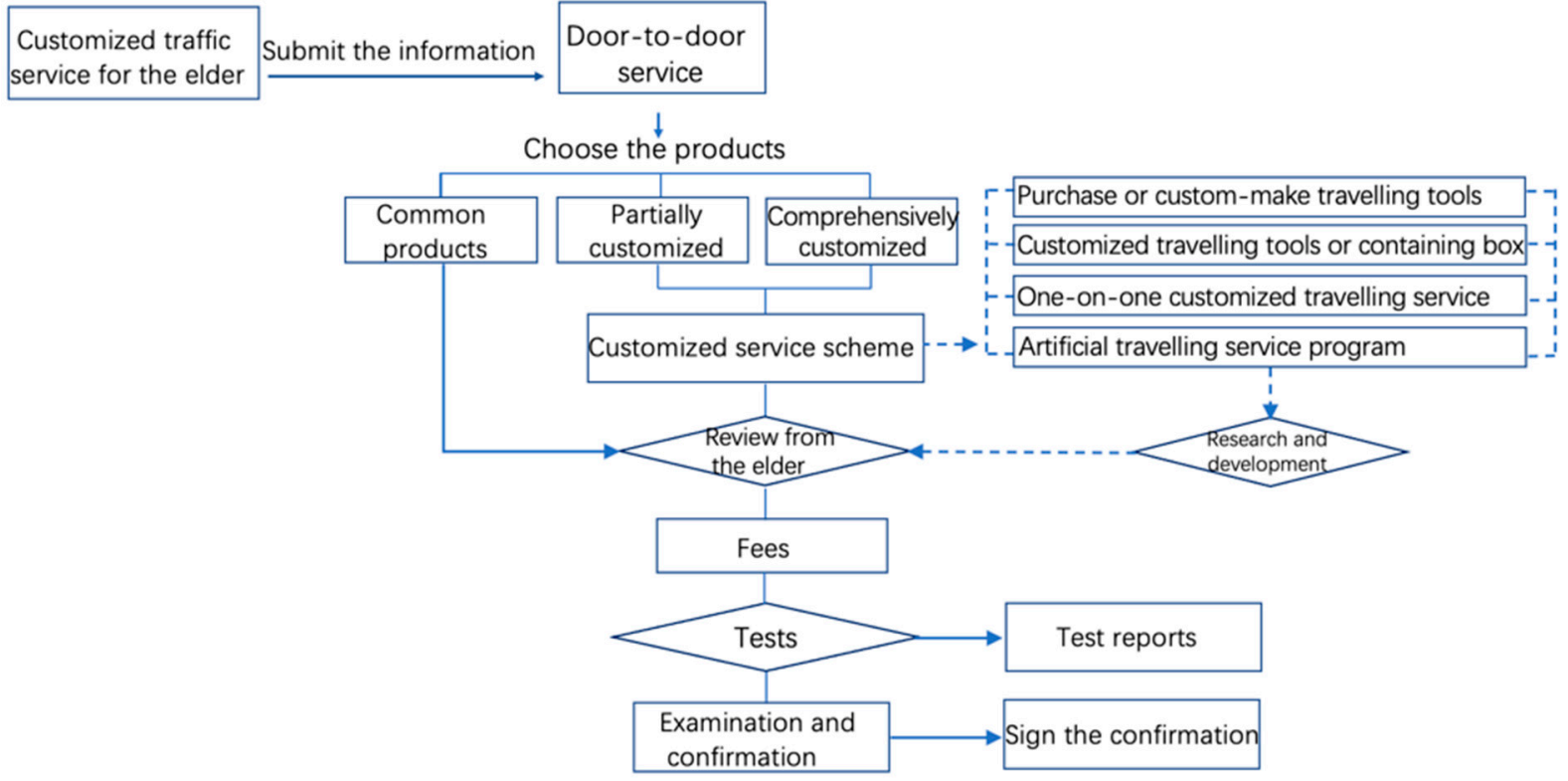

Figure 4. Customized senior-friendly transportation service process.

\subsection{Service Basis: Design Framework for Community Transportation Service System}

Only when the travel behavior, travel circumstances, location, products, information, personnel, emotional experience, and other aspects of older adults in the service system are understood can new service content be developed. The service relationship is established among older adults (service object), the operator (community transportation service staff), the supervisor (government, public service), and the manufacturer (manufacturer and designer of transportation vehicles).

Senior-friendly transportation service design should attend to both the cognitive laws and physiological limitations of older adults, users, and the community system of older adult travel activities in scattered mobile spaces, as well as the transportation tools used by the community, community auxiliary facilities, and service systems through exclusive sharing, network intelligence, and people-oriented design strategy. From the perspective of service design, senior-friendly travel will carry out organizational innovation 
in the exchange of transportation information, the renewal of transportation tools, and the intellectualization of travel equipment so as to build an overall new service experience. Figure 5 shows the design framework of the system as the service basis.

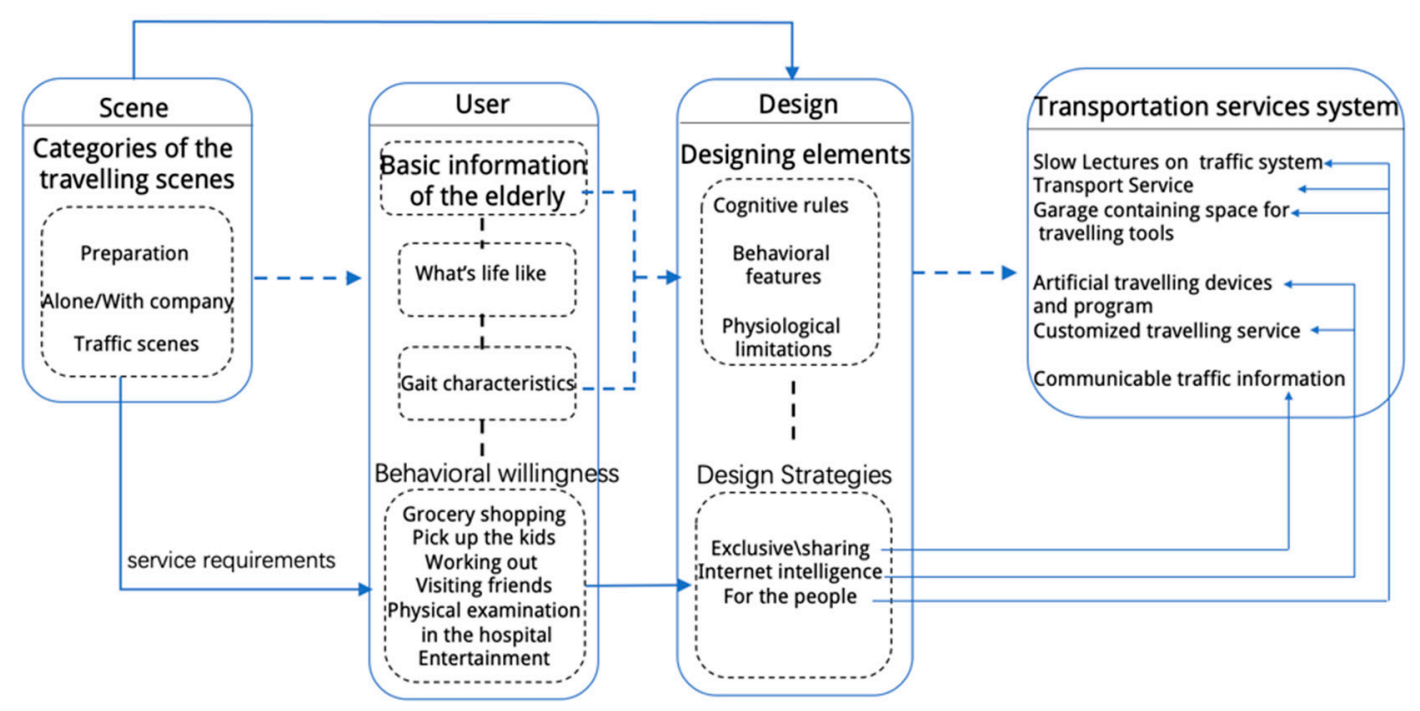

Figure 5. Design framework of the community transportation service system.

\subsection{Service Support: Senior-Friendly Community Service System}

When building an older-adult-centered service system, older people, as well as the service center, are affected by various stakeholders. Community stewards provide professional travel guidance, travel data detection, and vehicle purchase services. Community stewards provide transportation services, establish transportation service files for older adults, and offer professional travel suggestions. Family members can follow the travel process of older adults in real time and monitor their travel status. People can share travel information and establish close social relations with their friends, which can have a direct impact on their behavior, psychology, and travel habits. Community staff can provide professional services for older adults and guide their behavior in transportation activities (see Figure 6).

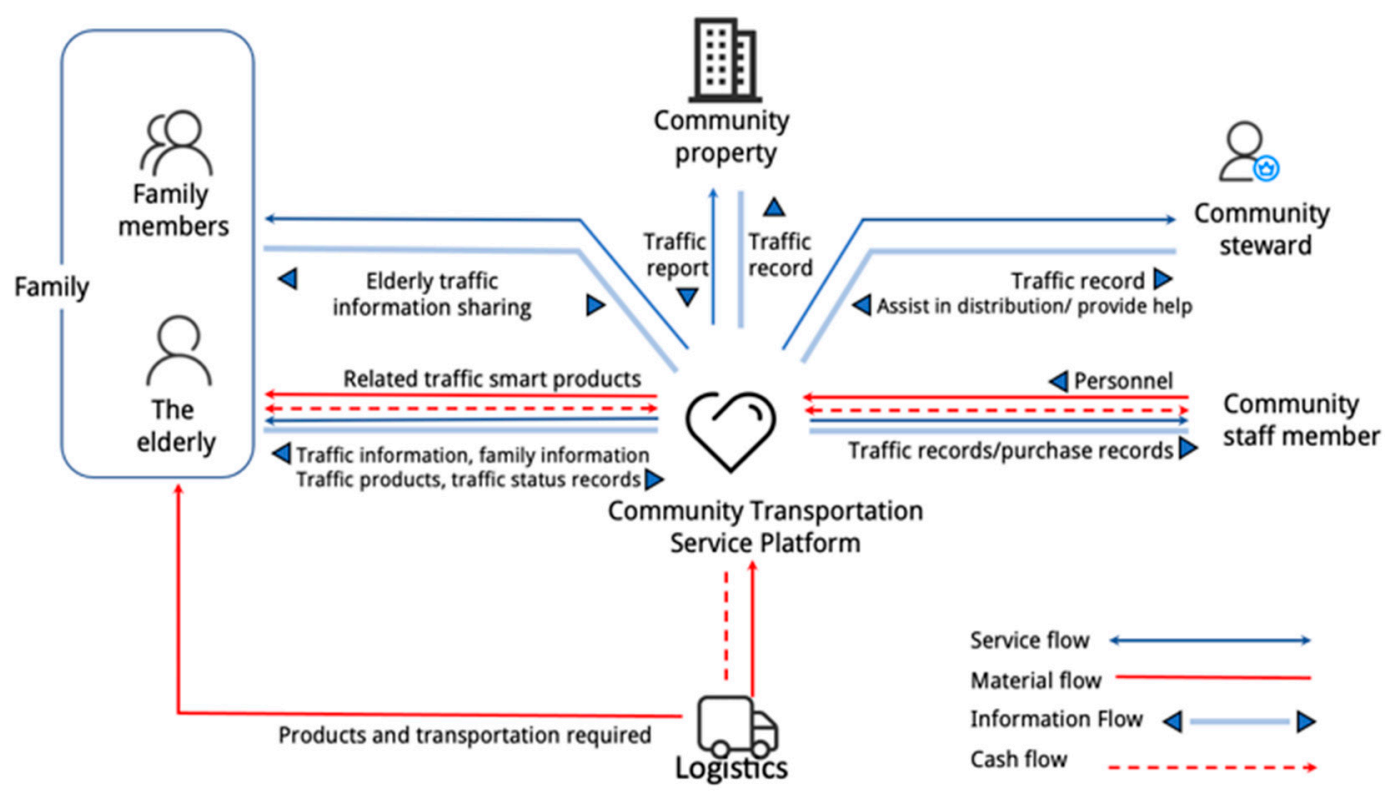

Figure 6. Senior-friendly transportation service system diagram. 
Building a "community-family" transportation service system under the transportation service mode, this new "Internet plus travel health" development mode will focus on the different functions of the community. The system will provide precisely targeted transportation services for older adults through the hierarchical classification of demand, improve the efficiency of travel communication, help older adults and their families to manage travel, and reduce the psychological burden of going out, specifically including the following:

A service platform serves as a bridge to connect older adults, their families, and communities.

Travel information is built at different levels through the platform to reduce the travel pressure on older adults.

Older adults will feel at more ease with the enhanced care from transportation services through customized community services.

Family members and property staff can track the travel of older adults through the service platform and get real-time information during the travel process for refinement of processes and provisions.

By attending professional traffic information presentations, older people's understanding of travel safety will be improved so that they can take preventive measures.

The platform will enable the user to purchase vehicles through it, to supervise and deliver products to the door in a comprehensive process, ensuring product quality and improving service efficiency.

\subsection{Service Effect: Community Stakeholder Design Strategy}

The term "stakeholder" originated in the business field. In the 1980s, R. Edward Freeman wrote the book Strategic Management: A Stakeholder Approach, which led to a spate of academic research on stakeholder theory. A stakeholder is a group or an individual that has influence over the achievement of organizational goals or is affected by organizational goals [45]. According to stakeholder theory, the interests, demands, policy influence, and will of various stakeholders play different roles in the implementation of public policy. Deviations from the actions and interests of key stakeholders may lead to unexpected policy results; therefore, it is necessary to effectively coordinate the actual behavior of various stakeholders through scientific incentive and restraint mechanisms and balancing of various interests. This research classifies stakeholders according to the level of influence and hierarchical importance based on stakeholder analysis. In this case, the service object is older adults and providers, including the external services and internal support of the community, as shown in Figure 7. External community transportation services are provided via a platform technology provider, logistics, tool suppliers, family members, other community services, and real estate companies. Internal services in the community transportation service include the community steward, property staff, and personnel of the marketing department. Stakeholders' participation is an important aspect of service design. Research and sorting are critical to facilitating the improvement and promotion of senior-friendly community transportation services. 


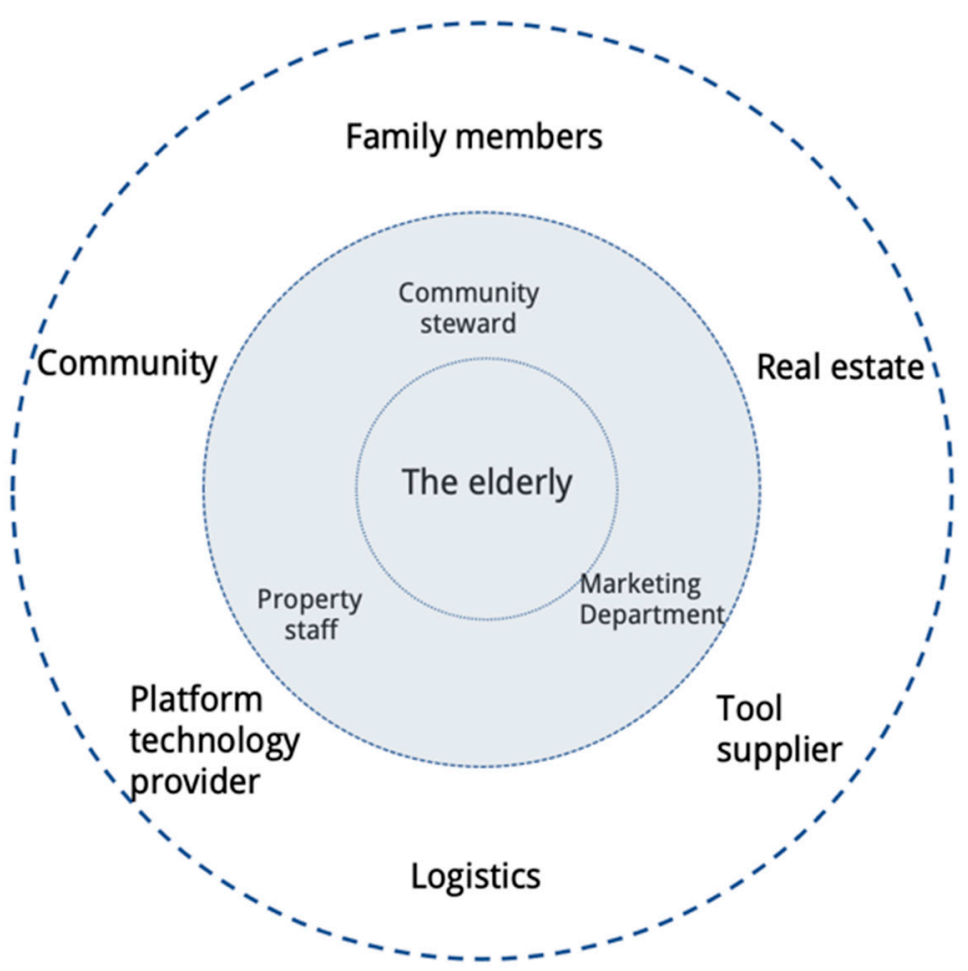

Figure 7. Community stakeholders.

\section{Conclusions}

This research proposed methods for solving the challenge of senior-friendly transportation service customization and contributes to the practice and basic theory of senior-friendly transportation service. In the context of increasingly exponential growth in population aging, examining the actual travel experiences and needs of older adults encourages communities to establish more diversified transportation services. The literature review in this study found minimal research on senior-friendly transportation services in the context of sustainable communities. To address this gap, the study develops a new senior-friendly transportation service model from the perspective of service design to ensure the inclusion and amplification of the interests of service stakeholders and rationalization of the service process. Seeking a breakthrough in practical understanding, a questionnaire survey and in-depth interviews were used to investigate the real needs of older adults users, a user journey map was adopted to summarize the identified complications, and a focus group interview was conducted to clarify the community transportation service system design strategy. Overall, the transportation service system we constructed, including service strategy, service foundation, service support, and service effect, ensures the operation of a senior-friendly transportation service, expands customized services, establishes a basic theoretical model of community transportation service, and proposes an integrated approach of online purchase and offline experience. This proposed model, grounded in actual experience, expands the research field regarding aging transportation services and enriches the research and theoretical aspects of senior-friendly transportation services.

\section{Research Content Innovation}

This paper systematically investigated, summarized, and examined seniors' practical, everyday paths and the potential field of senior-friendly transportation service using the grounded theory. The resulting proposed senior-friendly transportation service aimed to offer an executable scheme for the future construction of sustainable communities, providing a reference for research and practice regarding community transportation and other services. 
The paper proposed a senior-friendly transportation service system based on seniors' identified real-world experiences and needs. In view of the accelerated nature of population aging, a senior-friendly transportation service model was constructed. Few studies have examined senior-friendly transportation services and have mainly focused on senior-friendly residential spaces and products. This paper developed a senior-friendly transportation service model based on the perspective of service design through the summary and analysis of actual research for the first time, presenting a theoretical framework for promoting senior-friendly services overall. The service system can be used for more complex design tasks in the construction of senior-friendly communities as well as in the service design of other types of community support initiatives that are responsive to stakeholders' real-world experiences, needs, and concerns.

This study also has limitations. The data came from actual research, in-depth interviews, and a focus group as sources to further supplement the model; however, because of the regional limitations of this research sample and the fact that China's transportation service design is continuously evolving, a larger sample of seniors is needed to assess the reliability and validity of the questionnaire. Although the comprehensiveness and integrity of the text were considered as much as possible in the process of data coding, the data remain subjective. Although this research presented a theoretical discussion of a senior-friendly transportation service on the basis of practical investigation, the research on relevant theories is still extremely scarce. The need for senior-friendly transportation services is an increasingly serious consideration of aging in sustainable communities. To develop more in-depth senior-friendly transportation service understanding and approaches will require additional corresponding theoretical guidance.

In the future, by referencing the approach and research results of this study, other communities can identify their needs and establish their own senior-friendly transportation service platforms. Using this approach will aid the establishment of sound and sustainable cooperative transportation service systems that address the needs of all stakeholders and comprehensively improve community transportation services as a whole. The practical significance of this research is the construction of a proposed senior-friendly transportation system that can be directly used to inform and guide specific community practices. From a micro perspective, the community can directly emulate projects for other communities to address the landing, updating, and iteration of a senior-friendly transportation service system. The research also provides more specific practical references for real estate enterprises' integration of existing community transportation resources and formation of a practical, senior-friendly transportation service system, which will greatly improve the successful operability. From a macro perspective, this research has important practical significance for the whole community service research field to realize the sustainable development of customized transportation services. In addition, in future research, senior-friendly transportation service systems and artificial intelligence are expected to be combined to aid designers in managing the design task of more complex and detailed customized senior-friendly transportation services.

Author Contributions: Conceptualization, M.Z. and Y.P.; methodology, M.Z.; software, M.Z.; validation, M.Z.; formal analysis, M.Z.; investigation, M.Z.; resources, M.Z.; data curation, M.Z.; writing—original draft preparation, M.Z.; writing—review and editing, M.Z.; visualization, M.Z.; supervision, Y.P. All authors have read and agreed to the published version of the manuscript.

Funding: This research was funded by the Youth Foundation of Humanities and Social Science, China's Ministry of Education, grant number 21YJC760105.

Institutional Review Board Statement: Not applicable.

Informed Consent Statement: Informed consent was obtained from all subjects involved in the study.

Conflicts of Interest: The authors declare no conflict of interest. 


\section{References}

1. United Nations, Department of Economic and Social Affairs, Population Division. World Population Prospects 2019: Highlights; ST/ESA/SER.A/423; United Nations: New York, NY, USA, 2019.

2. People's Daily. Announcement of the main data of the seventh national census. Northwest Popul. J. 2021, $42,127$.

3. Ferris, R.E.; Glicksman, A.; Kleban, M.H. Environmental Predictors of Unmet Home-and Community-Based Service Needs of Older Adults. J. Appl. Gerontol. 2014, 35, 179-208. [CrossRef]

4. Meng, X. Community Governance Model: The Experience of Developed Countries and the Choice of China's Development. J. Guiyang Univ. Soc. Sci. 2019, 14, 63-69.

5. Xu, Q.; Chow, J.C. Exploring the community-based service delivery model: Elderly care in China. Int. Soc. Work 2011, 54, 374-387.

6. Xie, S. Comparison and Reference of Foreign Urban Community Management Models. Soc. Sci. 2004, 1, 47-50.

7. Roseland, M. Sustainable community development: Integrating environmental, economic, and social objectives. Prog. Plan. 2000, 54, 73-132. [CrossRef]

8. Zhao, K.; Chen, N. Urban sustainable community space construction. Planners 2013, 29, 109-110.

9. Cho, S.H.; Lee, T.K. A study on building sustainable communities in high-rise and high-density apartments-Focused on living program. Build. Environ. 2011, 46, 1428-1435. [CrossRef]

10. Muthuri, J.N. Participation and accountability in corporate community involvement programmes: A research agenda. Community Dev. J. 2007, 43, 177-193. [CrossRef]

11. Seyfang, G. Community action for sustainable housing: Building a low-carbon future. Energy Policy 2010, 38, 7624-7633. [CrossRef]

12. Wang, B.-C.; Chou, F.-Y.; Lee, Y.-J. Awareness of Residents Regarding the Construction of a Sustainable Urban Community: A Case Study of Action Research in Taiwan. Syst. Pract. Action Res. 2009, 23, 157-172. [CrossRef]

13. Liu, C.; Zhao, J.; Gao, X. Research on Urban Sustainable Community Based on Circular Metabolism of Nutrients. Urban Plan. Int. 2018, 33, 81-85. [CrossRef]

14. Seyfang, G.; Smith, A. Grassroots innovations for sustainable development: Towards a new research and policy agenda. Environ. Politics 2007, 16, 584-603. [CrossRef]

15. Dennis, L.M.; Liberman, A. Indicators of a Healthy and Sustainable Community. Health Care Manag. 2004, 23, 145-155. [CrossRef]

16. Rosenström, U.; Lyytimäki, J. The role of indicators in improving timeliness of international environmental reports. Eur. Environ. 2006, 16, 32-44. [CrossRef]

17. Bejleri, I.; Noh, S.; Gu, Z.; Steiner, R.L.; Winter, S.M. Analytical Method to Determine Transportation Service Gaps for Transportation Disadvantaged Populations. Transp. Res. Rec. J. Transp. Res. Board 2018, 2672, 649-661. [CrossRef]

18. Doi, K.; Sunagawa, T.; Inoi, H.; Yoh, K. Transitioning to safer streets through an integrated and inclusive design. IATSS Res. 2016, 39, 87-94. [CrossRef]

19. Too, L.; Earl, G. Public transport service quality and sustainable development: A community stakeholder perspective. Sustain. Dev. 2010, 18, 51-61. [CrossRef]

20. Rosenbloom, S. Sustainability and automobility among the elderly: An international assessment. Transportation 2001, 28, 375-408. [CrossRef]

21. Shostack, G.L. How to Design a Service. Eur. J. Mark. 1982, 16, 49-63. [CrossRef]

22. Hollins, G.; Hollins, B. Total Design; Pitman: London, UK, 1991.

23. Gao, Y.; Xu, X. Service Design: A New Concept of Contemporary Design. Lit. Art Stud. 2014, 6, $140-147$.

24. Government Digital Service. Government Design Principles. GOV.UK. 2012. Available online: https://www.gov.uk/guidance/ government-design-principles (accessed on 3 April 2012).

25. Baek, J.S.; Kim, S.; Pahk, Y.; Manzini, E. A sociotechnical framework for the design of collaborative services. Des. Stud. 2018, 55, 54-78. [CrossRef]

26. Van Holle, V.; Van Cauwenberg, J.; De Bourdeaudhuij, I.; Deforche, B.; Van de Weghe, N.; Van Dyck, D. Interactions between Neighborhood Social Environment and Walkability to Explain Belgian Older Adults' Physical Activity and Sedentary Time. Int. J. Environ. Res. Public Health 2016, 13, 569. [CrossRef]

27. Van Cauwenberg, J.; Van Holle, V.; Simons, D.; Deridder, R.; Clarys, P.; Goubert, L.; Nasar, J.; Salmon, J.; De Bourdeaudhuij, I.; Deforche, B. Environmental factors influencing older adults' walking for transportation: A study using walk-along interviews. Int. J. Behav. Nutr. Phys. Act. 2012, 9, 85. [CrossRef]

28. Mahmood, A.; Chaudhury, H.; Michael, Y.L.; Campo, M.; Hay, K.; Sarte, A. A photovoice documentation of the role of neighborhood physical and social environments in older adults' physical activity in two metropolitan areas in North America. Soc. Sci. Med. 2012, 74, 1180-1192. [CrossRef]

29. Moran, M.; Van Cauwenberg, J.; Hercky-Linnewiel, R.; Cerin, E.; Deforche, B.; Plaut, P. Understanding the relationships between the physical environment and physical activity in older adults: A systematic review of qualitative studies. Int. J. Behav. Nutr. Phys. Act. 2014, 11, 79. [CrossRef]

30. Van Holle, V.; Van Cauwenberg, J.; Van Dyck, D.; Deforche, B.; Van de Weghe, N.; De Bourdeaudhuij, I. Relationship between neighborhood walkability and older adults' physical activity: Results from the Belgian Environmental Physical Activity Study in Seniors (BEPAS Seniors). Int. J. Behav. Nutr. Phys. Act. 2014, 11, 110. [CrossRef] 
31. Dahan-Oliel, N.; Mazer, B.; Gélinas, I.; Dobbs, B.; Lefebvre, H. Transportation Use in Community-Dwelling Older Adults: Association with Participation and Leisure Activities. Can. J. Aging/Rev. Can. Vieil. 2010, 29, 491-502. [CrossRef]

32. Wang, Q.; Tang, S.; Hu, J.; Chen, X.; Wang, L. Performance Measurement System for Assessing Transportation Sustainability and Community Livability. Transp. Res. Rec. J. Transp. Res. Board 2015, 2531, 113-120. [CrossRef]

33. Thakuriah, P.; Sööt, S.; Cottrill, C.; Tilahun, N.; Blaise, T.; Vassilakis, W. Integrated and Continuing Transportation Services for Seniors. Transp. Res. Rec. J. Transp. Res. Board 2011, 2265, 161-169. [CrossRef]

34. Kim, S.; Ulfarsson, G.F. Transportation in an Aging Society. Transp. Res. Rec. J. Transp. Res. Board 2013, 2357, 109-115. [CrossRef]

35. Ling, S.; Ma, S.; Jia, N. Sustainable urban transportation development in China: A behavioral perspective. Front. Eng. Manag. 2021, 6, 1-15. [CrossRef]

36. Dehghanmongabadi, A.; Hoşkara, Ş. Determinative Variables Toward Promoting Use of Active Modes of Transportation: Enhancing Level of Sustainable Mobility in Communities. SAGE Open 2020, 10, 2158244020961118. [CrossRef]

37. Zakirova, Y.; Bilalova, I. Spatial Planning Techniques for Forming the Urban Environment in the Friendly City Concept. IOP Conf. Ser. Mater. Sci. Eng. 2021, 10, 032029. [CrossRef]

38. Brüchert, T.; Baumgart, S.; Bolte, G. Social determinants of older adults' urban design preference: A cross-sectional study. Cities Health 2021, 2, 1-15. [CrossRef]

39. Yu, J.; Ma, G.; Cai, S. Disparities in the provision of aging-friendly communities in old and new urban neighborhoods in China. Eng. Constr. Archit. Manag. 2019, 26, 1277-1293. [CrossRef]

40. Chen, Y.; Liu, G.; Chen, Z.; Zhao, C.; Guo, C. Conceptual planning and design of senior care community based on CCRC model. Light Ind. Sci. Technol. 2021, 37, 107-108.

41. Zhao, F.; Yang, P.; Yang, A.; Yang, D.; Li, M. Research on the Design of Public Service Facilities for the Elderly in Hebei Province. New Silk Road 2016, 10, 84.

42. Charmaz, K. Constructing Grounded Theory, 2nd ed.; SAGE Publications Ltd.: Thousand Oaks, CA, USA, 2014.

43. Turner, C.; Astin, F. Grounded theory: What makes a grounded theory study? Eur. J. Cardiovasc. Nurs. 2021, 20, 285-289. [CrossRef]

44. Fitzsimmons, F. Service Management: Operations, Strategy, Information Technology. Int. J. Serv. Ind. Manag. 2014, 10, $239-258$.

45. Edward Freeman, R.; Harrison, J.S.; Wicks, A.C.; Parmar, B.L.; De Colle, S. Stakeholder Theory: The State of the Art; Cambridge University Publications: New York, NY, USA, 2010. 